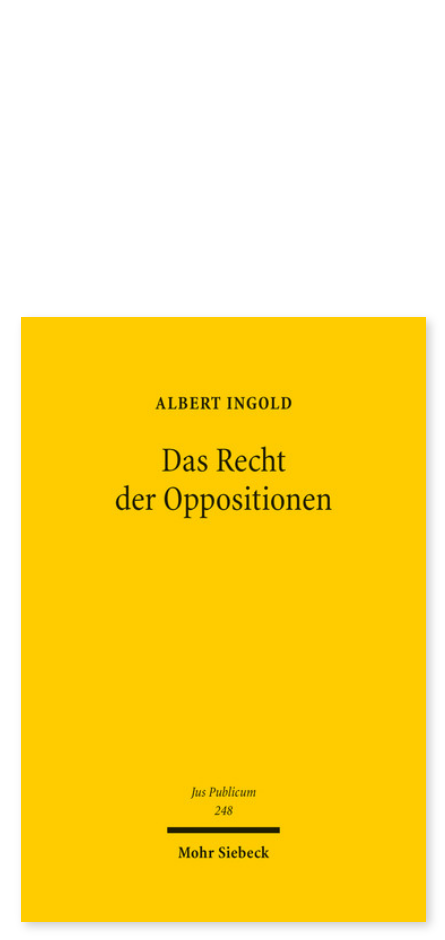

Albert Ingold

\title{
Das Recht der Oppositionen
}

Verfassungsbegriff - Verfassungsdogmatik - Verfassungstheorie

„Das Recht der Oppositionen« birgt ein mehrwertiges Spektrum: einerseits haben Oppositionen Rechte, andererseits sind Oppositionen ein Recht. Doch wie werden Rechte und Berechtigung von Oppositionen verfassungsrechtlich konfiguriert? Im Mittelpunkt der Untersuchung stehen parlamentsrechtliche Oppositionseinschreibungen, exekutive

Oppositionsstrukturen sowie gesellschaftliche Oppositionsfreiheiten. Das Panorama der Oppositionspotentiale wird konfliktund kontingenzorientiert als Pluralität des Opponierens verstanden: verfassungsrechtsdogmatisch vor allem in Form eines oppositionsbezogenen Freiheitsstatus und der Entfaltung von Oppositionen. Daraus entwickelt Albert Ingold eine Konzeption von Oppositionen als prozeduralisierte und pluralisierte Elemente des Verfassungsrechts, die insbesondere deren Legitimationsbedeutung hervorhebt und in der Grundlegung einer Verfassungstheorie der Oppositionen mündet.

Albert Ingold ist Professor für Öffentliches Recht, insb. Kommunikationsrecht und Recht der Neuen Medien an der Universität Mainz.

2015. XXIII, 738 Seiten. JusPubl 248

ISBN 978-3-16-153668-7

DOI 10.1628/978-3-16-153668-7

eBook PDF 159,00€

ISBN 978-3-16-153655-7

Leinen $159,00 €$

Jetzt bestellen:

https://mohrsiebeck.com/buch/das-recht-der-oppositionen-9783161536687?no_cache=1

order@mohrsiebeck.com

Telefon: +49 (0)7071-923-17

Telefax: $+49(0) 7071-51104$ 